\title{
THE EVOLUTION AND IMPACT OF MEDICAL ENTOMOLOGY
}

\author{
JOHN HULL IGRUNDY, MBE, FRES, FRSA*
}

Insects and arachnids attack man in two ways. Firstly, by Physical Attack, as when one or more of them bite or sting, and secondly, by Transmitting Pathogenic Organisms, as when a female Anopheles mosquito inoculates the parasites that cause malaria.

An example of 'physical attack' occurs each year during the short Arctic Summer of one to three months in northern Canada. Here, over an area of thousands of square miles, the thaw of the upper fow feet of frozen tundra liberates vast quantities of water which gather into puddles, streams and lakes. In this shallow water mosquito larvae of the genus Aëdes (Fig. 1) (which special-

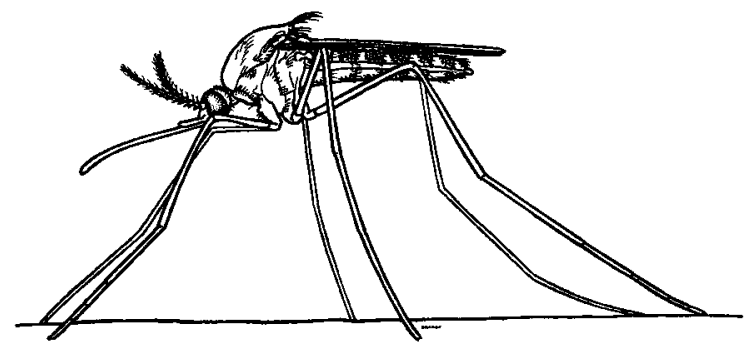

Fig. 1 Mosquito genus Aëdes

ises in breeding under adverse conditions), hatch from eggs which have remained dormant during the previous nine to eleven months of winter. By feeding voraciously on the plentiful supply of organic debris available, the aquatic larvae quickly pass through their four stages, then pupate, and finally become winged adult male and female mosquitoes. These mosquitoes are uncountable, for clouds of them may be seen as fog banks stretching from horizon to horizon, and as these Arctic Aëdes are among the largest and fiercest of their kind, it is easy to understand that no human work could proceed without the protection of special clothing and anti-mosquito measures. It is difficult, however, to appreciate the high rate of biting recorded of these mosquitoes, which rate is obtained by baring the hand and forearm to the elbow and with the aid of a stop-watch, counting the number of mosquitoes which alight to feed during a period of 60 seconds. By this method a rate of 280 per minute has been recorded. The ferocity of such an attack becomes apparent if the experiment is made of outlining an arm and hand on a blackboard or sheet of paper; then with a watch in hand, a series of chalk or pencil marks is dabbed rapidly between the outlines, in imitation of mosquitoes alighting to feed. By counting aloud and dabbing as quickly as

"Formerly: Lecturer in Entomology, Royal Army Medical College, Millbank (1945-1968). 
possible a rate of approximately 180 may be achieved. When one considers therefore, that not merely for one minute, but throughout the 24 hours of the day, clouds of large and hungry mosquitoes are endeavouring to pierce the defences of special clothing and repellents, it can be understood that this kind of physical attack seriously affects the operations of all human beings in these areas.

The late Professor Buxton once told me that when the permanent settlers of northern Canada became men with money in their pockets after working on the construction of army camps, they did not rush to spend their new wealth on provisions and luxuries, but on moving their homes to exposed promontories on lake shores, where the winds, uninterrupted by forest or scrub, were too strong for either mosquitoes or Simulium blackflies to remain for biting purposes. Here for the first time in their lives the children were able to play outside the cabins, a privilege previously impossible during the mosquito and blackfly seasons.

Simulium or biting blackflies (Fig. 2) have always been a seasonal menace in

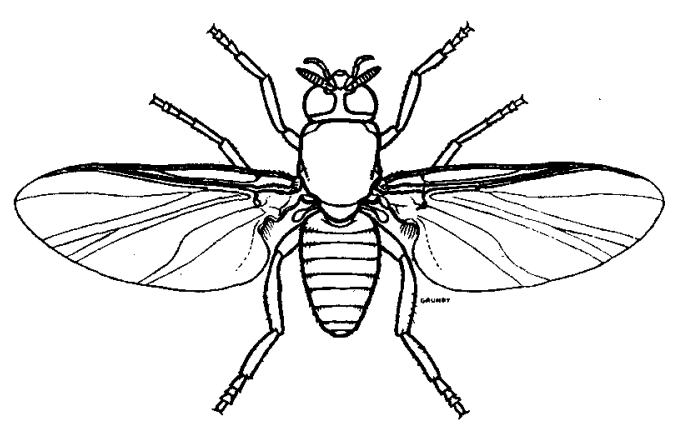

Fig. 2 Simulium or
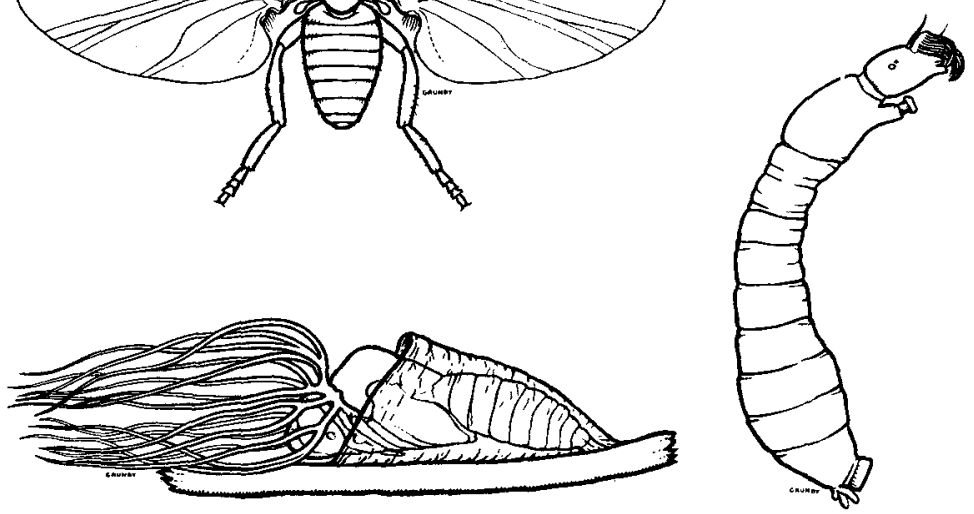

biting $\overline{\text { blackflies }}$

the tundra and forest regions of northern Canada, where their bites may cause an allergic condition known as 'bung eye', a swelling of the eyelids resulting in the victim being unable to see. This has been the cause of a number of deaths, when linked with exposure and shock through failure to make camp.

When the Danube basin suffers a drought year, conditions suitable for the mass breeding of blackflies may occur, and huge swarms of these small biting insects may drift on the prevailing winds to areas adjacent to the breeding grounds, killing by the shock of their multiple bites all animals unable to escape by going 
underground or into shelters. Men during 'fly years' protect themselves in the open by special clothing and by smokey fires termed 'smudges', or else by retreating into buildings. Simulium flies bite only by day, whereas mosquitoes typically bite during the night as well as by day if conditions are suitable.

Placing the problems of the physical attack of insects and their allies to one side, and examining instead the Transmission of Pathogenic Organisms by insect vectors, an entirely new world and concept of thought is encountered which has completely changed the course of most human societies.

For practical purposes, awareness of this world of microscopic organisms began with the Dutchman Leeuwenhoek, whose microscopes made it possible for scientifically minded men to observe structures previously invisible to the sharpest eyesight.

With the aid of his home-ground single (that is, not compound) lenses, he was able, among a host of other observations, to describe the red corpuscles of human blood, and to note that they were round in outline and not oval as in frogs. He further showed that weevil beetles in granaries and fleas in houses did not generate spontaneously in flour-dust or dirt respectively, but were developed from eggs, through grub stages which ate voraciously, and finally emerged as adults from a non-feeding pupa.

He also, in 1676, for the first time described "animalcules" in drops of rain water, that is, bacteria and protozoa, and claimed that these were universal, being carried by particles of dust blown about by the winds.

In spite of the publicity given to these microscopic animalcules and the permanent interest they aroused, two hundred years were to pass before it was realised that some of them could cause specific diseases.

Later, by means of special culture and staining techniques, Koch identified the tubercle bacillus in 1882 , and the cholera vibrio in 1884 with its typical transmission to man in drinking water.

The secret behind the discoveries of these and other important bacteria was simply the knowledge of how to stain them with aniline dyes, so that from a state of invisibility they could be seen under any reasonably high power microscope. To emphasise the importance of this usually overlooked discovery there is a record that Lister, after pondering Pasteur's work on putrefaction, entered a ward at three in the morning and lifted a patient's dressing to obtain a sample of pus. This he placed under his brass microscope, after removing the covering bell-glass, and gazed hopefully at the material on the slide. Of course, he was unable to distinguish anything, because he had not known how to stain the causative micro-organisms and so render them visible!

The techniques of staining were acquired slowly by medical men, perhaps because they needed demonstrations by an expert before understanding them, and as workers of different nationalities tended to be geographically separated, it was some time before the advancements of differential staining became common knowledge.

Thus it was, that although William Perkin, at the age of 18 years, had discovered mauve purple in 1856 whilst trying to synthesize quinine, and so found 
the first of the aniline dyes, it was not until 1879 that the German Ehrlich, first used acid and basic dyes (acid fuchsin and methylene blue) in combination for staining blood. Then in 1891, the Russian Dmitri Romanowsky used eosin and methylene blue for staining blood parasites, creating a standard that is still accepted today.

In spite of the advantage of this line of chemical research, most workers continued to study their microscopic preparations without differential staining. So in 1876 (the year Koch proved the Anthrax bacillus to be the causative organism of the anthrax disease) Patrick Manson, first on Formosa and later on Amoy on the Chinese mainland, proceeded to study filariasis with its dramatic symptom elephantiasis, which he was able to do without the benefit of stains, since most parasitic worms are large enough to be seen in unstained preparations.

In the course of his investigation, he became more and more impressed with the "microfilariae" in the blood of his filariasis patients exhibiting a nocturnal periodicity, as the immature worms were found to be swarming in the peripheral blood at night-time, though absent from this position by day.

Manson reasoned that this must be an effort of the parasites to obtain passage from man to man, and he could only interpret their coming to the surface at night as an effort on their part to enlist some nocturnal blood sucking insect to act as carrier. This he decided must be a mosquito.

To prove this theory Manson fed Culex fatigans mosquitoes on patients with microfilariae in their peripheral blood. He then dissected these mosquitoes, and traced the development of the immature worms from inside the stomach of the flies, through their gut wall into their blood circulation, and finally into the insects' thoracic muscles, and observed that in this situation the worms grew larger, developed a mouth, an alimentary tract and other organs, and concluded that "they were manifestly on the road to a new human host".

Unfortunately, although this work was spread over seven years, since his revised observations appeared in the Linnean Society's Transactions in 1884, Manson did not trace the passage of the mature microfilariae into the proboscis of the mosquito, from whence they pass to a new human host during the mosquito's next blood meal.

Being misled by a book on natural history which informed him that mosquitoes were as ephemeral as mayflies, he concluded they did not bite after oviposition but fluttered down to die on the water in which they had laid their eggs, and that filariasis was acquired by man through drinking water infected by such larvae as escaped from the bodies of the drowned mosquitoes.

Although an anonymous reviewer in the Veterinarian of March 1883, had suggested that if a mosquito could pierce human skin and suck up immature microfilarae it could possibly deposit the mature larvae on a new human host the next time it fed, Manson did not follow this lead, and it was left to the Australian Bancroft in 1889 to discover the true transmission cycle. Whilst Manson was still polishing his work on filariasis a historical discovery was made in regard to the most important disease in the world. 
On 6 November 1880, the young French Army surgeon Alphonse Laveran, whilst stationed in Algeria, correctly identified the parasites that cause malaria, and in a preparation of fresh unstained blood, among other forms, recorded the 'act of exflagellation' as part of the life of a living parasite. This discovery greatly interested both Manson and young Surgeon Major Ronald Ross of the Indian Medical Service. Manson was particularly interested because the flagella were reminiscent of microflariae, and Ross because malaria killed a yearly average of one and half million people in his India.

Although Manson did not himself hear about the parasites of Laveran until 1885, or see them until 1892 at the Seamen's Hospital at Greenwich (for a demonstration of method was usually needed to see these parasites for the first time in unstained preparations), yet he was in a position to show them to Ross in 1894, when Ross who had been unable to find them on his own account during a 12 year study of malaria, obtained an introduction to Manson, in order to be given a demonstration in his turn.

Manson was able to show the method of making a blood slide and recognising the parasites, at Charing Cross Hospital, and in November 1894, as they were walking along Oxford Street, Manson turned to Ross and said "Do you know I have formed the theory that mosquitoes carry malaria just as they carry filariae," and then proceeded to explain that he considered the malarial flagellae to be spores which enter water on the death of the egg laying female mosquito and so infect man when he uses the water for drinking purposes.

Ross was much impressed, and determined to investigate the matter on his return to India the following year. With the assets of enthusiasm, perseverance and a new microscope, but with the drawbacks of not knowing how to dissect mosquitoes, or to classify them into their different kinds, or how to stain microscopic preparations, Ross set to work in 1895, and in two years reached his first goal.

To begin with, he confused himself by experimenting with drinking water in which mosquitoes that had been fed on malaria patients had died. His first volunteer to drink such water contracted malaria, but the following 21 volunteers remained healthy! Ross's next attempts were to feed Culex and Aëdes mosquitoes on malaria patients, and to see if he could obtain the transmission of the parasites, either via the defaecations when deposited on human skin, or via the skin puncture while the female mosquitoes were feeding. These attempts failed, largely because Ross had used the wrong kind of mosquito, for it was not until later that he was to find that only members of the genus Anopheles (Fig 3) are capable of harbouring the parasites of malaria.

Finally, however on 20 August (known for years afterwards as 'Mosquito Day'), and again on 21 August 1897, he was at last rewarded by seeing rounded pigmented oöcysts on the stomach wall of some Anopheles stephensi which he had previously fed on a patient whose blood contained the crescent shaped female cells or macrogametocytes of falciparum malaria. These oöcysts he recognised immediately as malaria parasites because they were similar to the pigmented cells Laveran had described in 1880. 


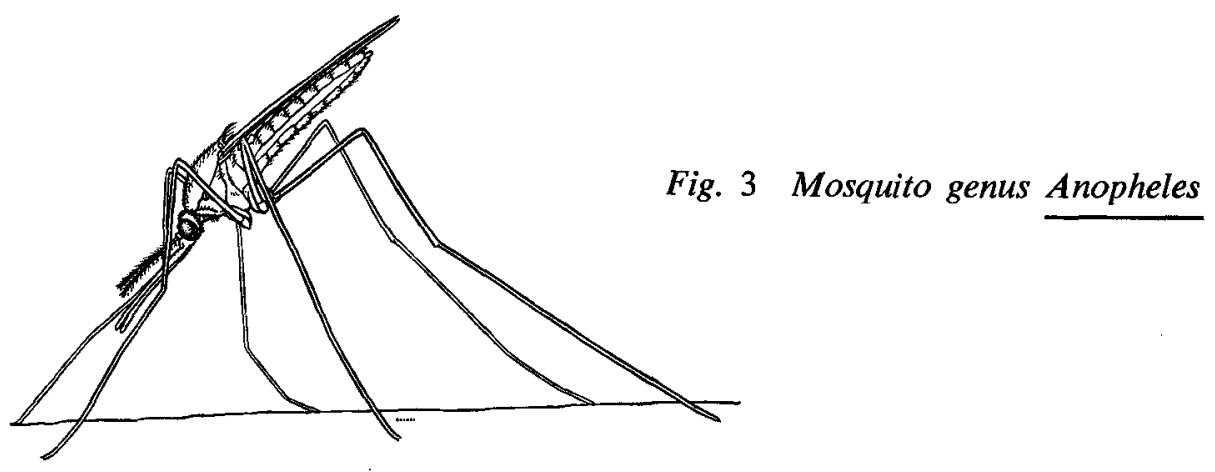

That he still accepted Manson's theory that the flagellate bodies of the male cells were spores, and that these were transmitted to man in drinking water does not detract from the fact that his first goal was the most important discovery mankind had yet been given, viz that an insect was at last proved to be the intermediate host of an organism responsible for a great epidemic disease.

The second goal was now obvious; to find how the parasites in the mosquito were conveyed to man. After some difficulty, Ross secured a post at Calcutta in 1898, but when he tried to get volunteers and patients for his experiments he could not obtain any cooperation, for the local population had recently been rioting against Mr Haffkine's anti-plague inoculations.

Ross, therefore returned to bird malaria in sparrows. That he should do this so readily may have had some connection with an episode that occurred early in 1897. On this occasion he had witnessed a flagellum from a male parasite struggling inside a female parasite, but with Manson's spore theory in his mind he had dismissed the incident as that of a spore endeavouring to get out of a cell, instead of in!

The true sex significance of this was discovered the same year by a young American student William MacCallum who was studying avian malaria in crows. When Ross heard the truth of the act of exflagellation he wrote that "he had felt disgraced as a scientist ever since!" With this in his mind it was natural that he should turn to bird malaria in the absence of human volunteers. Also being now freed from preconceived ideas of spores and drinking water, he was more able to trace the complete cycle - from man to mosquito, and from mosquito to man.

His careful investigations of the mature oöcysts on the mosquito stomach revealed that they finally burst in situ and evacuated their contents into the blood stream of the mosquito, so Ross set himself to find where these contents went. They appeared to consist of masses of tiny motile rods which had their greatest concentration in the thorax. Close observation, for Ross did not then know how to dissect a mosquito, finally revealed the rod-like organisms or sporozoites thickly packed in the cells of the salivary glands. Once this was seen it was obvious that parasite-laden saliva of the feeding mosquito would be infective to a susceptible host, and this was proved by Ross when he infected 22 out of 28 sparrows by inducing infected mosquitoes to feed on the birds. 
His second goal was achieved in 1898 , and the final goal of proving the mosquito transmission of malaria in man was achieved in the following year by Manson, who obtained some female Anopheles mosquitoes which had been fed on a malaria patient in Rome. These infected mosquitoes were allowed to bite two healthy volunteers (one being Manson's only son), in London, where there was no malaria, and as both developed the disease, the final proof of insect-borne transmission was beyond doubt.

Between the two dates 20 August 1897 and 13 September 1900 (when Thorburn Manson began his malarial fever in London) lies the dividing line between the Past and the Present in History, between the Ancient World and the Modern World.

Before the double ruled line of these two dates lay the long history of Homo sapiens during which he struggled blindly against fate and disease, when women had to breed continuously, as do the lower animals, in order that sufficient progeny should survive to assure continuance of the race. During this long period religions were largely rituals of supplication to cosmic gods to grant succour to those who prayed, and invariably these religions were accompanied by a symbol of terror called the Devil, named by the ancient Hebrews better than they knew Beelzebub 'King of the flies'. Before the discoveries of Ronald Ross, mosquito-borne malaria, flea-borne plague, louse-borne typhus, louse and tick-borne relapsing fevers, mosquito-borne yellow fever, fly-borne typhoid fever, the fly-borne dysenteries and fly-borne cholera, not only took their steady toll of life each year and from each generation, but every ten years or more appeared as epidemics, and every fow hundred years in a world-wide pandemic form, as in the Black Death of the 14th Century and the Plague of the 19th Century.

After the year 1900 mankind has been able, not only progressively to discover the causes of the great epidemic diseases that before had seemed to be curses upon the human race, but also increasingly to find means for their control and eradication.

From this date also became possible our vast cities with their swarming populations, the huge armies of over ten million men in the field, the incredible revolutions of politioal and social life that are unique in the world's history, and our present achievements regarding the atom and the conquests of outer space. To some extent insects have now ceased to be man's greatest enemy, for he has assumed that role himself, since whatever he now fears most, he is himself responsible for creating.

Once insects and their allies were proved the carriers of epidemic diseases, either by simple mechanical or complioated cyclic transmission, it only became a matter of expending sufficient mental energy, time and money to find the causes and in many cases the cures for those arthropod-borne diseases which had previously kept mankind in such merciless subservience.

The foregoing is proof of the importance of the quite recently evolved science of Medical Entomology, without which most people alive today would not have been born, 'or if brought into the world would have been cut off in 
early life by epidemic disease. To explain this more clearly there are two aspects of Medical Entomology which it is vital to understand. First, the Practical or Functional aspect, where the entomologist tracks down and identifies the arthropod pest, finds out its habits and life history in relation to disease and endeavours to control or eradicate it. Second, the inevitable and usually unforeseeable consequences of this practical work.

A good example of the Practical side of Medical Entomology is concerned with the invasion of tropical South America by the most infamous mosquito vector of tropical Africa Anopheles gambiae. This mosquito has two notorious characteristics. It thrives best in the vicinity of human habitations and it quickly colonises itself in shallow, sunlit rain-puddles. It is thus able rapidly to increase its range during and at the end of the rainy season, in a manner not known of any other mosquito.

Therefore in March 1930, when Shannon the entomologist found some 2,000 Anopheles gambiae larvae in a pool in a hayfield behind a sea wall in north east Brazil, his report to the health authorities at nearby Natal city, that a dangerous vector had been carried from Africa to South America, seemed to him most urgent news. No particular notice was taken of this report however! Five weeks later, when the worried entomologist returned to examine the mosquito situation, he found that malaria had broken out in epidemic form, so that not only was it necessary to distribute medicines, but also food to enable the local population to survive. His survey at this time revealed that the vector mosquitoes had extended their range by about one kilometre, and the epidemic itself at last stirred the city authorities into action, so that the Brazilians antiAëdes aegypti yellow fever personnel were appealed to help apply Paris green arsenical dust to the known Anopheles gambiae breeding waters. This plus the advent of the dry season, brought about a substantial lowering in the number of cases of malaria. The entomologist's recommendation that the sea walls be broken through to allow water flooding of the hayfields was resisted so persistently by vested interests that nothing was ever done in this direction, although this simple control measure would have quickly destroyed all the gambiae at their original focus. It is a historical fact that the vested interests of rich and poor always resist control measures that affect their income, no matter how serious the danger is! The entomologists now reported that Anopheles gambiae larvae were to be found over an area of over some six square kilometres, but little was done to limit their breeding until a devasting outbreak of malaria in January 1931 forced the Federal Government itself to take action, and with the aid of the Rockefeller Foundation a campaign was finally launched that eradicated gambiae from this area by 1932. Application of Paris green larvicide formed the basis of control in this instance.

Further surveys by entomologists failed to find any gambiae whatever, either adults or larvae, but mosquitoes are difficult creatures to overcome, and so instead of this being the end of the story it proved to be but a beginning, for soon after the 'all clear', rumours of epidemic outbreaks of rural malaria began to come in from the surrounding countryside. 
Fortunately a barrier of open sea lies to the east of this north east tip of Brazil, while to the south and west are swift rivers, contrary winds and mountain barriers. At the nonth west however, Anopheles gambiae somehow managed to slip through and colonize certain valleys which were much more suitabie to its habits than its original point. However, as five years of drought concurred with this silent invasion, which drought was severe enough fully to occupy the Government in relief schemes for alleviating the suffering of the agricultural villages, the gambiae population, with its attendant malaria, was allowed to occupy more and more territory without any particular outcry.

Then the dry seasonal weather changed, and the flood rains began. The long inland river valleys became sheets of deep and shallow water. The roads were submerged and prevented ingress of supplies and egress of people wishing to escape, and under these conditions Anopheles gambiae became ubiquitous, and malaria exploded into full scale epidemics among the marooned population.

The general belief was that the north east of Brazil would be completely depopulated by malaria, aided by starvation and emigration, and this tragic state of affairs lasted, in spite of national efforts to combat it, until the year 193.

The devastation that occurred has been described as similar to Mauritius in 1866 and 1867, the Punjab in 1908, Ceylon in 1935 and but for prompt action in Egypt in 1945. This was simply the result of one species of Anopheles mosquito being allowed to establish itself in a new country despite the warnings of entomologists.

At last however, the combined resources of the Brazilian Government and the Rockefeller Foundation mounted eradication attacks with Paris green arsenicals which, starting at the perimeters of the stricken areas, gradually worked inwards, eventually destroying the invading gambiae by 1940 .

It is noteworthy that at the time other South American Governments were extremely loath to join any common fund for use against the Anopheles gambiae, either hoping that eradication would be successful before the invading mosquitoes reached their territory, or else out of carelessness, engendered by lack of imagination. This very common attitude is one of the main reasons why Medical Entomology should not be allowed to lapse when it is not actively fighting some outbreak, for like the fire service in a well organised community, one never knows when a situation will need controlling, and that quickly if there is not to be a catastrophe; for the official mind, fully occupied with administrative problems, is rarely in a position to organise quickly against disasters, if expert help is not at hand. That the complacement modern world is likely to run into insect borne catastrophes in the near future is already threatened by the alarming rate with which arthropod vectors are developing genetic resistance to each new insecticide as it is introduced. DDT, BHC, Diedrin and Lindane, are already ineffective in several parts of the world and chemists are hard pressed to keep ahead of these resistant strains.

As to the means by which gambiae reached South America, the evidence points to French destroyer postal vessels which made fast runs from Dakar in 
Africa, and regularly anchored off the particular portion of the coast where the gambiae were first found, and it is believed that these 'avisos' were responsible for carrying adult mosquitoes across the Atlantic. The break through of the vector to the north west similarly, is believed to have occurred either by coastal shipping or by road vehicles carrying the adults, all of which shows how easy it is for man himself to be a 'carrier' of disease vectors!

Finally, after giving this example of practical entomology, there is left the most important aspect of all "The inevitable and unforeseeable consequences of the practical work", for it must always be realised that Medical Entomology in practice alters the evolved balance of nature, as it has affected man, animals and plants during the past half a million years.

This shows itself in two simple and distinct ways. Firstly "By allowing human populations to increase explosively, in the absence of the checks that diseases and starvation previously imposed". Secondly "By endowing the increased population with new mental health and energy" so that the people of countries and continents who before were considered listless and peaceful, have become violently nationalistic or otherwise aggressively group-conscious and combative.

The first aspect, that of population increase has been very seriously studied by persons and councils responsible for World Health Planning, and two clear schools of thought have emerged, both desirous of ultimately benefiting mankind. One school feels it is wrong, suddenly to introduce the benefits of medical entomology and upset the age old balance in the densely populated areas of the world, until such time as these countries and continents have been taught how to limit their birth rate. For it is feared that these populations, suddenly freed from endemic and epidemic disease, may simply exchange death by disease for death by starvation.

The other school of thought feels strongly that help must always be given to rid populations of disease, and that such 'bridges' as arise in populations beyond food supplies are to be crossed when they are arrived at. Whichever method is adopted, the consequences to us personally and to our descendants is a matter for future life and death.

The second effect, that is increased mental health and energy has not received the same attention as the problem of world population, although its effects are much more topical. In this respect it is interesting to look at a map and note the world-wide stations of medical discoveries, many of them by Army medical officers of different nationalities, and then to examine the recent political changes that have taken place in these areas.

The Dutchman Leeuwenhoek gave the microscope with which to see pathogenic organisms. The German medical officer Koch gave the cause of tuberculosis and cholera and its mode of transmission, after investigations in India and Egypt. The Scottish medical officer Manson discovered the mosquito host of filariasis and elephantiasis after work in China. The Australian Bancroft gave the complete transmission cycle of filariasis from Australia. The French Army surgeon Laveran recognised the parasites of malaria during work in Algeria. The 
Russian Romanowsky gave the differential stain by which blood parasites may be viewed and studied. The British Army medical officer Bruce gave the tsetse fly carrier of nagana and sleeping sickness in Africa. The IMS surgeon Ross gave the mosquito transmission cycle of malaria, during studies in India, and so the list might go on with many names, including those who gave their lives directly in the cause of medical entomology.

These discoveries however, as the 20th Century gathered way, became more and more associated with control measures, until we find in many countries that control or eradication schemes have replaced the endeavour to find new vectors and disease organisms, and the effects of this are worth thinking about.

To sum up, what does the impact of medical entomology ultimately mean to us and our children? It means that scientific mankind must learn to think in world wide terms or suffer terrible reverses of his own making. He must learn to consciously limit his numbers and he must continue to fight disease, not only because he considers human life to be sacred, but because a modern adult human being has cost so much in parental effort and social expenditure to bring to maturity. Furthermore, human beings who are living in this generation of machine miracles and scientific opportunities, must utilise their knowledge with a minimum of personal greed and lust for power, and with a maximum of gratitude and appreciation for those generous and dedicated students of science and the arts who have raised, and continue to raise, all mankind towards the appreciation of civilised culture.

\section{Honorary Consultants}

Mr. A Wallace, MB, FRCS, has been appointed Honorary Consultant in Plastic Surgery to the Queen Elizabeth Military Hospital, Woolwich, with effect from 6 June 1980. He succeeds Mr P G Sandon, MB, FRCS.

Mr R Sandon, MB, FRCS, has been appointed as Honorary Consultant in Plastic Surgery to the Army. This is a new appointment. 